\title{
Simulating digital dividend auctions: Service neutrality versus dedicated licences
}

\author{
José Luis Gómez-Barroso , Asunción Mochón , Yago Sáez , Claudio Feijóo
}

\section{A R T I C L E I N F O}

\section{Article history:}

Received 16 January 2011

Received in revised form 23 April 2011

Accepted 27 April 2011

Available online 5 May 2011

\section{Keywords:}

Digital dividend

Spectrum management

Auctions

Mobile communications

Television

Scarce resources

\begin{abstract}
A B S T R A C T
The award of the digital dividend can consolidate auctions as the preferred mechanism for spectrum allocation. Knowing in advance an estimate of what the results of an auction with these characteristics could be would be unquestionably useful for those in charge of designing the process, even if at the end another method such as a beauty contest is chosen. This article provides a simulation of a digital dividend auction in a major-type European country. In one of the scenarios, the spectrum is not pre-allocated to any service in particular (service neutrality) while in the remaining four, blocks of spectrum are pre-allocated to DTT, mobile multimedia and mobile broadband communications. The results of the simulations reveal that the service neutrality scenario maximizes revenues for the seller and that, in general, DTT operators would seem to have fewer opportunities as the spectrum packaging is less protective for them.
\end{abstract}

\section{Introduction}

The radio electric spectrum is a scarce resource, a resource for which demand is growing quickly as the proliferation of innovative services that require spectrum for operating continues. The process of digitising television broadcasting signals is already under way around the world. Indeed, many countries have already completed the "analogue blackout". Transmission of existing television channels in a digital format requires a much smaller spectrum than does an analogue broadcast. Thus digital broadcasting makes it possible to free up a sizeable portion of the spectrum for new services in spite of new television channels being added. These "new" available resources are referred to as the "digital dividend".

The allocation of this (eventual) digital dividend opens an infrequent (given the importance of the band and the potentially high number of licences) process of spectrum allocation. Who will be granted the dividend's usage rights, under what rules and for what services, are and will be vitally important questions for the electronic communications sector. In fact, it is one of the most relevant events among those that will have a global impact on the whole sector in the near future.

The decision regarding the dividend appears in a time of change as regards the radio electric spectrum management (refer to Feijóo et al., 2009), where a current of opinion favourable to the introduction of market economy criteria seems to be

\footnotetext{
* Corresponding author. Tel.: +34 913988115; fax: +34 913987821.

E-mail addresses: jlgomez@cee.uned.es (J.L. Gómez-Barroso), amochon@cee.uned.es (A. Mochón), yago.saez@uc3m.es (Y. Săez), cfeijoo@cedint.upm.es (C. Feijóo).
} 
consolidating. In fact, many national authorities in charge of spectrum management ${ }^{1}$ as well as the European Commission ${ }^{2}$ or the $\mathrm{ITU}^{3}$, have released documents supporting the modification of the current spectrum management models. Moreover, the reform of the spectrum regulatory framework is already effective in several countries.

One of the key aspects of this reform is precisely the introduction of modifications in the licence-allocation mechanisms. Beauty contests have been the predominant mechanism for primary spectrum allocation, although not the only one. Indeed, the usage of auctions is not unknown in the sector. Licences have been auctioned for years and in a great deal of countries. The auctioning of $3 \mathrm{G}$ mobile communications licences by several European countries during 2000 and 2001 was a point of inflection in the consideration of auctions as a spectrum allocation mechanism, regardless of the failure or success of the licencees. The allocation of the digital dividend can be a second turning point. Particularly when considering the fact that the American FCC stepped forward by allocating via auction an important part of its digital dividend, a procedure that ended on March 18, 2008.

Auctions are thus being weighed up by any administration in charge of allocating the digital dividend. What will other countries do, for example, in Europe? In Germany, the majority of funds raised from the spectrum auction that came to an end on May 20, 2010, were earmarked for $800 \mathrm{MHz}$ frequency (digital dividend) licences. Some other European countries have already made public plans in this direction, with the United Kingdom (its regulator, Ofcom) being the one that seems to have progressed the most as regards the procedures prior to the auction.

In order to choose whether or not to use the auction (or even to establish the rules of the beauty contest, should this option have been chosen) it would be interesting to anticipate what the results of an eventual auction could be. This article provides a simulation of a digital dividend auction in a major-type European country. Actually, it deals with five scenarios: the first presents no restrictions for the allocation (service neutrality) while in the other four, the spectrum has been packaged by the regulator, i.e., spectrum blocks are pre-allocated to different services. This provides additional richness to the results since apart from the absolute values (obviously conditioned by the assumptions with which the model has been designed), it allows comparing different situations.

The article is divided into four parts. The first one presents the variables with which the model has been built, based on a prior discussion on what could have been the options chosen. Section 3 details the scenarios features and presents the tool used for simulating the auctions. Subsequently, the results obtained are described and discussed. The conclusions end the paper.

\section{Characteristics of an auction for the allocation of the digital dividend}

Any auction presents four basic aspects: what is auctioned, who participates in the auction, what is the value the participants assign to the auctioned goods and, last, what are the rules of the auction.

\subsection{Size of the digital dividend}

The diffusion in digital format of previously existing television channels requires a considerably smaller bandwidth than that used in the past for the same number of channels. However, almost all countries are allocating additional frequencies for digital terrestrial television (DTT) in order to provide for the broadcasting of new channels, this reducing in fact the extent of the digital dividend.

In most cases where a decision has been taken, the digital dividend has been estimated around $100 \mathrm{MHz}$. For example, Ofcom, the British regulatory authority, has rated the digital dividend in $128 \mathrm{MHz}$. This is a similar quantity as that rated in Japan $(118 \mathrm{MHz})$ and in the United States $(108 \mathrm{MHz}$ in the $700 \mathrm{MHz}$ band, which gave name to the already completed auction).

\subsubsection{Assumption used in the model}

It is supposed that the digital dividend is $120 \mathrm{MHz}$. For the auction, it is divided into 15 lots of $8 \mathrm{MHz}$ each. The division into $8 \mathrm{MHz}$ channels has two reasons:

- It is the size of the existing channels in UHF band.

- The Geneva-06 Agreement (signed on the occasion of the Regional Radio Conference 2006) allocated the digital dividend spectrum in $8 \mathrm{MHz}$ channels across Europe for other uses compatible with digital broadcasting.

The licences are awarded for a national scope. It is more spectrally efficient, in general, to allocate spectrum across the country as a whole rather than at a more granular level (it avoids the need for different services using the same frequency

\footnotetext{
${ }^{1}$ As an example in Europe, that of the British regulator Ofcom. Refer to the document "Spectrum framework review: Implementation plan" released in 2005 (available at http://www.ofcom.org.uk/consult/condocs/sfrip/). The FCC quotes as their first objective in their Web site: "advance spectrum reform by developing and implementing market-oriented allocation and assignment reform policies"; refer to http://www.fcc.gov/spectrum/

2 "Policy aims to facilitate spectrum access across the EU through market mechanisms". Communication of the Commission "i2010 - A European Information Society for growth and employment" COM (2005) 229 final. Brussels, 1.6.2005.

${ }^{3}$ Refer to, as an example, the ITU document "Market mechanisms for spectrum management". It is a document that summarises the results of a workshop with the same title held in Geneva, Switzerland, from 22 to 23 January 2007 (available at http://www.itu.int/osg/spu/stn/spectrum/workshop_proceedings/ STN.MMSM-2007-PDF-E.pdf).
} 
channel to be geographically separated). Additionally, it is more realistic to think that the participants in an auction will be interested in providing national services (except for local television, which it is not considered in the model).

\subsection{Agents interested in participating in the auction}

As regards other frequencies, the UHF band presents a series of characteristics that provide an optimal combination of range and data capacity. Better propagation means fewer base stations. For example, at $3.5 \mathrm{GHz}$, the signal covers a cell size of about $5 \mathrm{~km}$ while at $700 \mathrm{MHz}$ it is about $10 \mathrm{~km}$; thus the network infrastructure investment (CAPEX) for a wireless operator would be nearly seven times higher if they have to use $3.5 \mathrm{GHz}$ compared to the larger cell sizes at $700 \mathrm{MHz}$ (Forge et al., 2008). Additionally, the low signal attenuation in the presence of obstacles guarantees adequate coverage inside buildings without the need for additional equipment, thus minimising the infrastructure costs required for deployment.

This makes almost all service and applications providers using the radio electric spectrum interested in participating in the sharing out of this "newly available" spectrum. The list of possible services the digital dividend could be allocated to includes the following:

- Additional television channels (standard or high definition; national or local coverage).

- Multimedia (television, on-demand video, music, radio) for mobile receivers.

- Mobile communications (voice transmission and broadband connection for data transmission).

- Other short range, low power device-related services such as medical telemetry, Radio Frequency Identification (RFID), Near Field Communications (NFC), etc.

- Non-commercial services: defence, security, emergencies or other public services.

- Other services yet to be developed: it has even been set forth to reserve certain bands for their future allocation to usages yet to be defined.

\subsubsection{Assumption used in the model}

The participation in the auction is restricted to companies interested in operating in three of the markets described above: digital terrestrial television, mobile multimedia and mobile communications. These are the most lucrative markets and, thus, in an auction such as the one to be simulated, with licences awarded for a national scope, most probably only them could have actual possibilities of obtaining spectrum.

We establish a total of fifteen participants in the auction: eight previously present in any of these markets and seven newcomers. Their characteristics are described below:

- Digital television broadcasters ${ }^{4}$ (four)

Their interest is to obtain more spectrum for broadcasting new television channels, be they standard (DTT-SD) or high definition (DTT-HD) (and in one of the cases, both types simultaneously). Additionally, one of these companies is attempting to also enter the mobile multimedia market (Mob MMedia).

- Mobile communications operators (four)

We consider two possibilities: two agents already hold spectrum in the $900 \mathrm{MHz}$ band (they are the current holders of the first GSM licences awarded) and the other two do not have any spectrum in this lower band (they have accessed the market more recently).

Since the four of them are already present in the market, we assume that the additional spectrum would be allocated both to voice and data services (Mob Comm Voice + Data), although we suppose that one of the agents is particularly interested in strengthening their mobile broadband access (Mob Comm Data centric). Additionally, two of these companies are interested in including also multimedia services (Mob MMedia) as a part of their client offer.

\section{- Newcomers (seven)}

We consider that they only compete for entering into one of the aforementioned markets.

Table 1 summarises the characteristics of these participants in the auction. In the "Level of confidence" column there are three possibilities (low-medium-high) which correspond with the perception of the possible profitability that the awarded spectrum would provide. The following section explains this in further detail. Likewise, that same section explains the contents of the "Lots required" column.

\footnotetext{
${ }^{4}$ For our purposes, we do not distinguish among broadcasting infrastructure providers (managing a transmission network), broadcasting service providers (offering TV services in a package) and broadcasters (the companies commissioning, producing and aggregating TV content into channels). Whatever of them could be involved in spectrum auctions. However, the first two are, more and more, particularly in a number of countries, the ones actually involved.
} 
Table 1

Agents participating in the auction.

\begin{tabular}{|c|c|c|c|c|}
\hline & Company & Target market & Level of confidence & Lots required \\
\hline B1 & TV Broadcasters & DTT-SD & Medium & $3-12$ \\
\hline B2 & & DTT-HD & Medium & $3-15$ \\
\hline B3 & & DTT-SD/DTT-HD & Low/Low & $3-15$ \\
\hline B4 & & DTT-SD/Mob MMedia & Low/Medium & $1-15$ \\
\hline B5 & Mobile operators & Mob Comm (Voice + Data) & Low & $1-8$ \\
\hline B6 & & Mob Comm (Voice + Data)/Mob MMedia & Low/Medium & $1-14$ \\
\hline B7 & & Mob Comm (Voice + Data)/Mob MMedia & High/Low & $1-14$ \\
\hline B8 & & Mob Comm (Voice + Data)/Mob Comm (Data centric) & High/Low & $1-15$ \\
\hline B9 & New entrants & DTT-SD & High & $3-12$ \\
\hline B10 & & DTT-HD & High & $3-15$ \\
\hline B11 & & Mob Comm (Voice + Data) & High & $1-8$ \\
\hline B12 & & Mob Comm (Data centric) & Medium & $1-8$ \\
\hline B13 & & Mob Comm (Data centric) & High & $1-8$ \\
\hline B14 & & Mob MMedia & Low & $1-6$ \\
\hline B15 & & Mob MMedia & High & $1-6$ \\
\hline
\end{tabular}

\subsection{Spectrum assessments carried out by the participants}

Spectrum value for operators could be broadly divided into an engineering value and a strategic value: the engineering value reflects the less expensive configuration of the network infrastructure obtained when more spectrum is available to the operator's network designers; the strategic value reflects the expected position in the market an operator will hold as a result of the assigned spectrum and the possible exclusion of another operator that would have otherwise come into play (Sweet et al., 2002). Note that both values are mutually interdependent as a less expensive network configuration also helps to improve the market position of an operator.

Both calculations are extremely complex: the first one requires engineering design exercises which are often quite particular and difficult to generalise. Even more complicated is the second one. In markets such as that of the ICT, the result will always be uncertain. Recently, real options have been proposed as a more adequate methodology to include these effects in telecommunications infrastructures cost calculations (see Lyoo et al. (2006), and a general overview in Alleman et al. (2008)). Anyway, as Ofcom (2006) states: "we can be confident that the value of the resource as a whole is large, but there is significant uncertainty over the value of individual uses. This reflects, above all, the uncertainty that is inherent in fast-moving markets - where changes in technology and consumer preferences cannot be reliably foretold".

\subsubsection{Assumption used in the model}

In the Ofcom document that consults on the proposed approach to the awarding of the digital dividend spectrum (Ofcom, 2006) there are assessments on the value that a certain additional fraction of spectrum could have for different services. These figures have been obtained as a result of a model that intends to identify the incremental producer and consumer value which is generated by using the available UHF spectrum compared to other alternatives (other spectrum bands or delivery platforms). What is provided is the private value: the sum of industry producer surplus (profits) and consumer surplus (individual's willingness to pay in excess of the market price) ${ }^{5}$. The model was refined and actualised in Ofcom (2007). See details in Annex I.

As said above, the difficulties of an analysis of this nature are obvious. Ofcom itself assumes the limitations of the calculations: "the high level of uncertainty and the complexity of some of the inter-relationships between services mean that this type of modelling can at best provide an order of magnitude assessment of value". It is also obvious that none of the figures quoted in the document can be taken directly as an indication of auction proceeds. However, after being submitted to certain adaptations, they are valid for their use in a simulation exercise as the one we intend to perform. The adaptations carried out to transform them into spectrum valuations (valuations, not bids) by the participating companies are as follows:

- The total surplus is divided in equal share (50/50) between consumers and producers.

- For each service, Ofcom designs two scenarios: high and low value scenario. In our model, it translates into the maximum

(a) and minimum (b) of the valuations bracket.

Instead of using this broad bracket for any company, we have decided to approach reality and consider different maximum and minimum valuations. Therefore, within this bracket, three intervals are designed which would correspond to different assessments (or confidence levels as regards the future profitability) carried out by the agents ${ }^{6}$ low [a; $(a+b) / 2$ ];

\footnotetext{
${ }^{5}$ The "external value" (externalities), which consists of "broader social/citizen" value plus other sources of external value, is excluded. Costs and benefits are measured in a time period of 20 years from 2007 onwards using a discount rate of $3.5 \%$.

The level of confidence of each agent is included in Table 1. They have been assigned trying to reflect different possible situations that actually occur in real markets.
} 
medium $[(3 a+b) / 4 ;(a+3 b) / 4]$; high $[(a+b) / 2 ; b]$. Note therefore that the valuation of each agent is no longer a single value but that it can take any value within an interval.

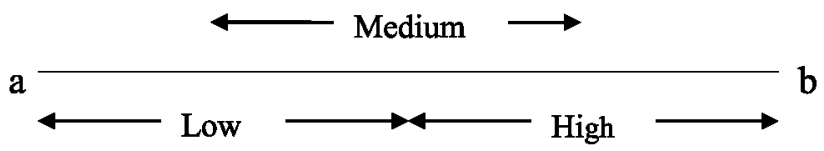

The valuations given refer to an optimum amount of spectrum which is specified in (or can be deduced from) the scenarios designed for each service by Ofcom. For each agent, that will be the optimal amount of lots they compete for. Higher or lower amounts are "modified" by a coefficient which is higher the further away it is from the optimal value (refer to Annex I). Additionally, for some services there exists a minimum amount of lots (the service cannot be provided with less lots) or a maximum amount of lots (additional lots would be unnecessary under the current market conditions).

\subsection{Auction model}

When there are multiple objects to be sold, like spectrum licences, the first decision the agency in charge of managing the auction must take is whether to sell the objects separately in multiple auctions or jointly in a single auction. If every licence is sold separately (be it in sequence or simultaneously), the participants face the so-called "aggregation risk" (or exposure problem), which occurs when what is considered as the "necessary minimum" number of lots is not won.

If the seller chooses to sell all the licences at a time in a single auction, the question about how to package the goods offered for sale must be faced. To solve the exposure problem bidders can be allowed to choose the packages for themselves. This type of auctions are known as combinatorial or package auctions.

Combinatorial auctions are particularly appropriate if there are strong complementarities between licences (synergies) as well as substitution possibilities (see Cramton, 2007). These auctions allow the participants to bid both for complete packages (all-or-nothing bids) as well as for individual licences.

Finally, there are a series of basic parameters that must be defined in any auction, regardless of the characteristics of the auctioned good:

- Bidding procedure: open price auctions/sealed auctions.

- Determining the price the auction winner will pay: pay what you bid/second highest bid (Vickrey-Clarks method).

- Existence or not of a reserve price.

\subsubsection{Assumption used in the model}

A combinatorial first-price sealed bid auction without reserve price will be used. This auction model is fast, transparent and not prone to the appearance of collusion among the participants.

For this auction format, bidders are allowed to submit in one single round as many bids as they wish for any combination of available lots. Then, the auctioneer determines the combination of feasible bids that maximises the revenues, i.e., solves the winner determination problem (WDP). After that, winners have to pay what they bid for the awarded items.

In order to simplify the calculations, we consider that the auctionable goods are completely homogeneous, which is approximately true in this case (frequencies are close enough to consider that the lots are close substitutes).

We also consider that the valuations are equal regardless of the lots being contiguous or not, which is not strictly true. However, a generic approach simplifies the process for bidders, who only have to express the number of lots they want at a particular price. The seller can then organise a follow-up process to actually allocate spectrum in such a way that, for example, contiguous spectrum can be guaranteed.

\section{Scenarios and methodology}

Five different scenarios have been defined. In the first scenario (scenario $\mathrm{N}$ ), service and technology neutrality has been chosen and, as a consequence, the lots are not preallocated to any service. In the remaining scenarios, amounts of spectrum are allocated to different services (refer to Table 2).

Each of the S scenarios actually implies three (or two) different auctions (one per service, bidding the number of pre-allocated lots shown in Table 2). This means that eleven auctions have been simulated (ten partial auctions corresponding to the $\mathrm{S}$

\footnotetext{
${ }^{7}$ In economic terms, this means that complementary and substitution effects between lots simultaneously exist. Goods are substitutes (subadditive values) if earning one item reduces the value of earning more items; goods are complements (superadditive values or synergies) if already having one item increases the value of awarding another one (Ausubel et al., 1997).
} 
Table 2

Spectrum packages on scenarios $\mathrm{S}$.

\begin{tabular}{|c|c|c|c|c|c|c|c|c|c|}
\hline & \multicolumn{2}{|l|}{ S1 } & \multicolumn{2}{|l|}{ S2 } & \multicolumn{2}{|l|}{ S3 } & \multicolumn{2}{|l|}{ S4 } & \multirow[t]{2}{*}{ Bidders (defined in Table 1 ) } \\
\hline & Lots & $\mathrm{MHz}$ & Lots & $\mathrm{MHz}$ & Lots & $\mathrm{MHz}$ & Lots & $\mathrm{MHz}$ & \\
\hline DTT & 12 & 96 & 8 & 64 & 4 & 32 & o & 0 & $1-2-3-4-9-10$ \\
\hline Mobile MMedia & 0 & 0 & 2 & 16 & 7 & 56 & 5 & 40 & $4-6-7-14-15$ \\
\hline Mobile Comm & 3 & 24 & 5 & 40 & 4 & 32 & 10 & 80 & $5-6-7-8-11-12-13$ \\
\hline & & 120 & & 120 & & 120 & & 120 & \\
\hline
\end{tabular}

Table 3

Seller's average income $(€ \mathrm{M})$.

\begin{tabular}{|c|c|c|c|c|c|c|c|c|c|c|c|}
\hline & \multirow[t]{2}{*}{ Lots } & \multicolumn{2}{|l|}{ DTT } & \multirow[t]{2}{*}{ Lots } & \multicolumn{2}{|c|}{ Mobile MMedia } & \multirow[t]{2}{*}{ Lots } & \multicolumn{2}{|c|}{ Mobile Comm. } & \multicolumn{2}{|l|}{ TOTAL } \\
\hline & & Total & Per lot & & Total & Per lot & & Total & Per lot & Total & Per lot \\
\hline $\mathrm{N}$ & & & & & & & & & & 1927.6 & 128.5 \\
\hline S1 & 12 & 832.0 & 69.3 & 0 & - & - & 3 & 288.9 & 96.3 & 1120.9 & 74.7 \\
\hline S2 & 8 & 573.8 & 71.7 & 2 & 283.9 & 141.9 & 5 & 491.4 & 98.3 & 1349.1 & 89.9 \\
\hline S3 & 4 & 158.9 & 39.7 & 7 & 1006.0 & 143.7 & 4 & 404.0 & 101.0 & 1568.9 & 104.6 \\
\hline S4 & 0 & - & - & 5 & 776.3 & 155.3 & 10 & 914.0 & 91.4 & 1690.3 & 112.7 \\
\hline
\end{tabular}

scenarios in addition to that of the $\mathrm{N}$ scenario). DTT-reserved spectrum auctions are attended by companies interested in launching both new SD and HD channels; mobile communications reserved-spectrum auctions include those both agents classified as "voice + data" and "data centric", while mobile multimedia auctions include players interested in these services, be them newcomers, DTT or mobile communication companies. Bidders interested in operating in more than one market participate in the partial auctions with the valuation regarding that specific service, while in scenario $\mathrm{N}$ both values are added up.

In order to move from valuations to actual bids, two additional steps are required. First, the exact value given by each participant is determined in each experiment by fitting a Gaussian distribution to the valuation interval. This value is the maximum players should be willing to bid in an auction. The second step is to select a "strategy" for the bid. This is done selecting a value between 0 and 1, again using a Gaussian distribution, for each agent and experiment. The final bid is then calculated as the product of the value and the strategy selected.

Once defined the model, each of the scenarios have been run 100 times. To solve the award process, an efficient simulator for combinatorial first-price sealed bid auctions has been implemented. To work out the winner determination problem an $\mathrm{A}^{*}$ search algorithm has been developed (Hart et al., 1968). The $\mathrm{A}^{*}$ tree representation used is based on a branch on bids (BOB) formulation with a simple but efficient heuristic function based on revenues (for a further understanding of this algorithm, see Sáez et al., 2008).

\section{Results of the experiments}

Annex II provides a comprehensive perspective of the results.

Table 3 provides a comparison of the seller income in each of the five scenarios (as an average of the 100 experiments). The service neutrality model is clearly the most profitable one for the seller. The $\mathrm{S}$ scenarios increase in profitability the less spectrum is pre-allocated to television, which is in agreement with the fact that this is the service that less bids per lot. The number of lots preallocated to each service does not cause major differences in the average price paid per lot, except in the case of DTT in scenario S3 where the number of lots (four) is far below the "desired" amount of spectrum and, to a lesser extent, the 10 lots for mobile communications in scenario S4 (in this case, due to the "excess" in the number of lots).

The amount paid per lot in each of the services also gives an idea of which are the most successful bidders when there is no packaging of the spectrum. The central part of Fig. 1 presents the global results of scenario $\mathrm{N}$. The agents interested in television receive almost no spectrum. On the other hand, the bidders that are more interested in mobile multimedia seem to achieve in average better results than those focused on mobile communications. However, it has to be considered that, in the words of Ofcom, mobile multimedia is "an emerging service and as such the uncertainty surrounding future demand is particularly large". In this simulation exercise, this translates into the fact that the fork comprising the valuations is broader than that of the remaining services. But also, and more importantly, that the continuous update that the values would require would be deeper in the case of mobile multimedia. Indeed, they should probably be lowered due to present economic crisis $^{8}$.

\footnotetext{
${ }^{8}$ It may be valuable to perform a sensitivity analysis of the simulation using other valuations. This is a difficult task as there is not any other set of assessments similar to the ones offered by Ofcom. A more recent document (Analysys Mason et al., 2009) includes an overview of the different studies that have estimated potential values of the digital dividend. All those studies, however, give aggregated estimates of private and external value, far insufficient for our model.
} 


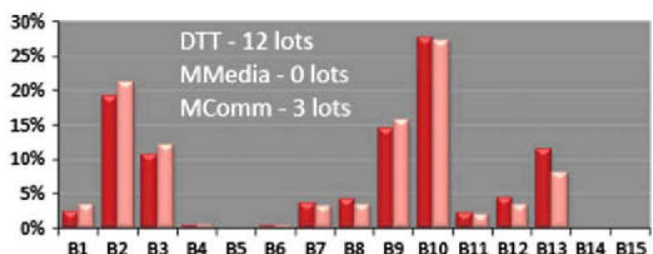

S1

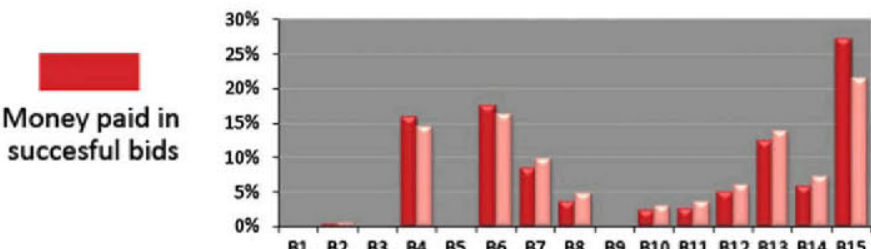

\section{S2}

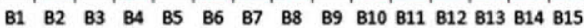

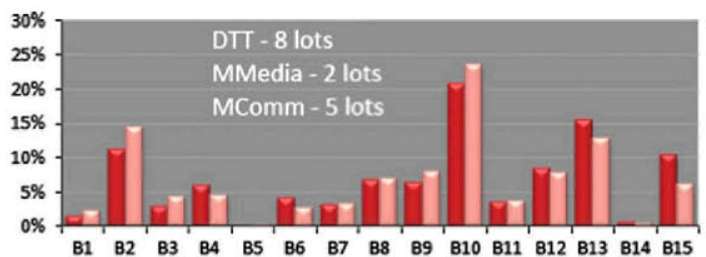

S3

\section{S4}
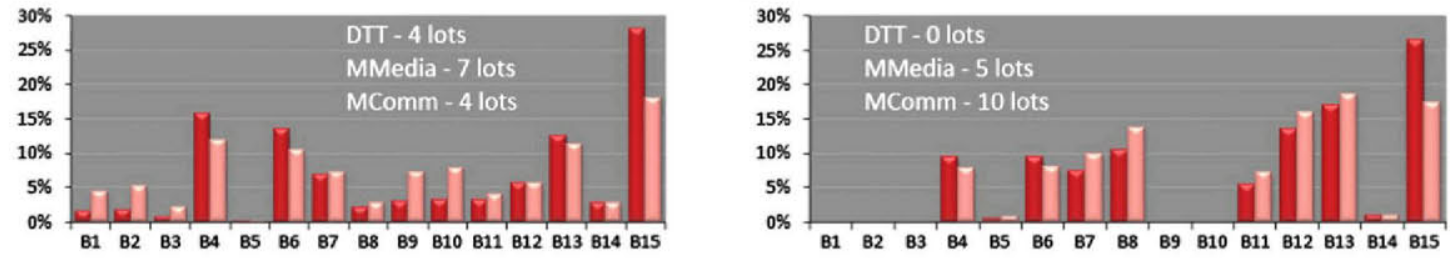

Fig. 1. Scenario N and Scenarios S - Aggregated results from 100 repetitions. Horizontal axis shows bidder identifier (from B1 to B15) - vertical axis is the percentage distribution of lots and total amount paid.

Digital TerRestrial TELEVISION

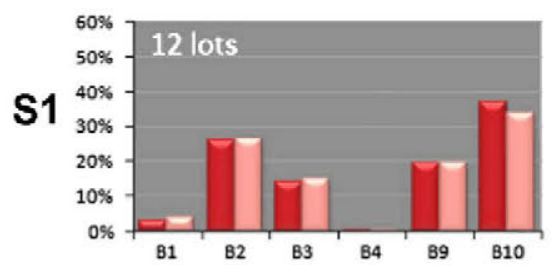

S2
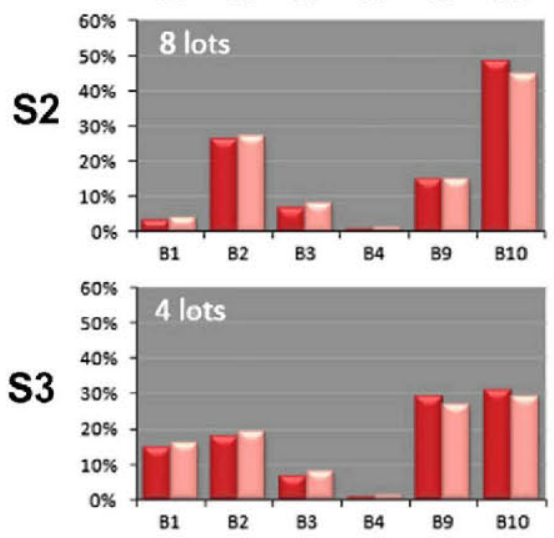

S4
MOBILE MULTIMEDIA
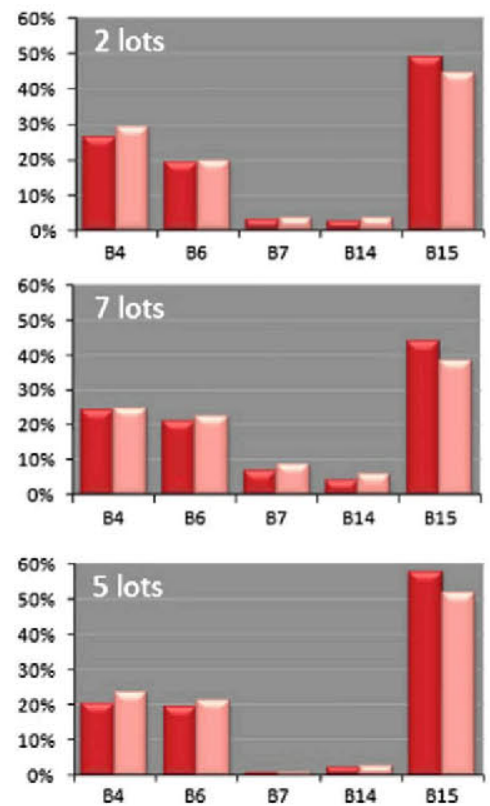

Money paid in succesful bids

\section{MOBILE COMMUNICATIONS}
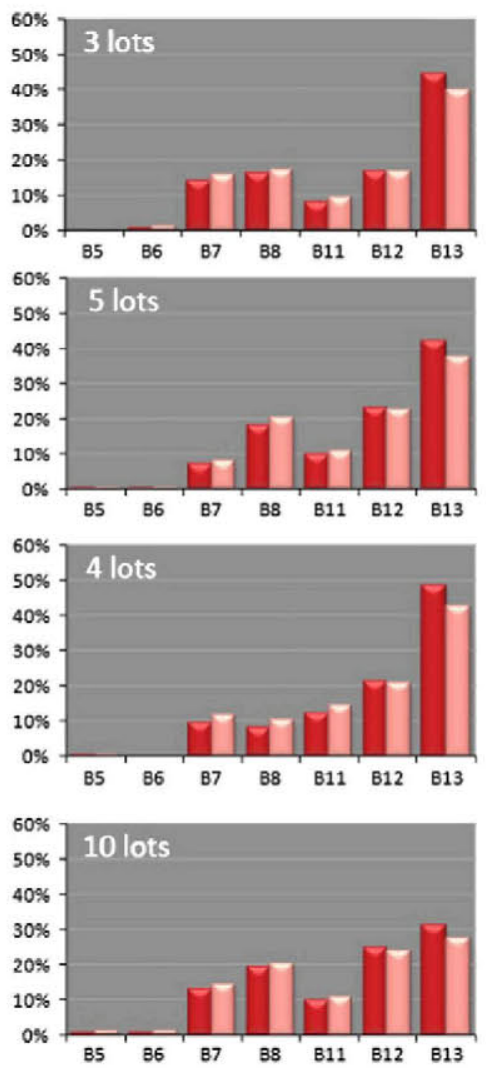

Awarded lots

Fig. 2. Scenarios S - Results per bidder. Horizontal axis shows bidder identifier (from B1 to B15) - vertical axis is the percentage distribution of lots and total amount paid. 
The surrounding graphs of Fig. 1 show the results of the S scenarios when all the partial auctions are added up. Fig. 2 breaks down the results of these partial auctions. Generally, the spectrum is concentrated among the stronger agents (those who have a highest "level of confidence" in Table 1). Their dominance is attenuated when there is "abundant" spectrum (S4, mobile communications) or when the number of lots is below what is considered optimal (S3, DTT). It is also important to underline that the companies that most value the spectrum, and which are awarded the most lots, pay more (percentually) than the amount of spectrum that they receive (also percentually).

\section{Conclusions}

Using the auctions as a means for allocating spectrum, two objectives can be pursued: revenue maximisation and, second, efficiency optimisation, that is, putting the spectrum in the hands of those best able to use it from a triple (technical, economic and social, see Feijóo et al., 2009) perspective. Both objectives are not always compatible: auction rules that focus on revenue extraction may conflict with the goal of maximizing social welfare (Hazlett and Muñoz, 2008).

This article has shown that when the first of these objectives is pursued, and provided the conditions under which the different auctions are carried out are identical, the service neutrality model must be the one chosen. Any other scenario, even giving more lots to mobile multimedia, which is the service that more bids per lot, would result in a lesser income for the seller ${ }^{9}$.

How accurate are the results obtained in the simulation in terms of possible seller's income? It has to be said that Ofcom itself, in the document on which the valuations are based, only intends with its model to determine "an order of magnitude". Logically, the specific circumstances of each market and the general economic situation existing when the auction is carried out will decide the results.

More important than the above: should the service neutrality model be chosen as well when the options are assessed in terms of efficiency?

If any of the S scenarios is chosen, it is because the regulator is assuming that scenario N will cause some sort of "market failure" and, therefore, it is not the most efficient solution. These eventual market failures would be originated by the nonfulfilment of "legitimate policy objectives" (for instance, cultural matters), by transaction costs or, more importantly, by the existence of externalities.

The Ofcom assessments do not include an exact calculation of the external value although they do roughly estimate that in the case of mobile communications it would represent up to $15 \%$ of private value while, for example, for DTT-HD it would only represent up to $5 \%$. Other works provide more precise data. In a more in-depth study, and comparing several options, the key finding of Forge et al. (2008) is that the use of the digital dividend by the mobile sector is "highly positive for the European economy over the next decade and more" while the "use of the released spectrum by broadcasting has much less impact on the economy; the difference in results arises mainly from the significant productivity gains throughout the EU economy", estimated (by 2020) as much as an additional $0.6 \%$ GDP growth per year in the mobile case when compared with broadcast TV. On the opposite side, Oliver\&Ohlbaum and DotEcon (2008) state that in a study carried out for the European Broadcasting Union, DTT "generates significant public value for society that would not be visible in any hypothetical contest for spectrum with other uses, and cannot easily be replicated through provision of TV using other platforms" in addition to the fact that the medium-term value that could be created by other uses of UHF spectrum "appears modest".

In addition to this evident lack of agreement on the social welfare results of the allocation, the risk of regulatory failure when opting for a specific spectrum divided scenario in order to avoid the concentration of spectrum for a particular type of service has to be added. Ofcom (2007) identifies a whole list of uncertainty sources that make difficult the decision of the regulator and increase the risk of unintended consequences:

- The wide range of potential uses of the spectrum that can be identified and the fact that many of these potential applications would be new services.

- The existence of alternatives to the products and services that could be supplied using the digital dividend and the development of alternative platforms for delivering a particular service.

- The uncertainty about the likely response of producers and consumers; in particular, consumer preferences in relation to the consumption of media.

- The high likelihood of further innovation occurring that could affect possible uses of the digital dividend.

One solution could be that proposed by Cramton (2002) who states that the best policy on spectrum restrictions is a middle ground, where binding caps are imposed in initial auctions, but these caps give way once it is believed that, in his own words, "vigorous competition has been established". This would lead to choosing one of the S scenarios and introducing a reform in the spectrum management which, in addition to the allocation mechanisms, would affect the transmission of rights allowing for a service-neutral secondary spectrum trade.

\footnotetext{
${ }^{9}$ Consider that in scenario $\mathrm{N}$ mobile multimedia companies can bid for the whole of lots. Moreover, the amount paid per lot by mobile multimedia in scenario $\$ 4$ ( 5 lots preallocated to mobile multimedia) is higher than in scenario $\$ 3$ (7 lots).
} 
Based on all of the above, should the $\mathrm{N}$ scenario be chosen or one of the $\mathrm{S}$ scenarios instead? And, if this is the case, which one? The results of the simulated auctions described in this article do not provide for any efficiency assessment as such. However, the different scenarios do provide a forecast of what the results would be in terms of eventual spectrum distribution and this is, indeed, a significant datum for deciding on how the digital dividend should be used.

\section{Appendix A. Annex I}

Definition of the services considered for spectrum valuations:

- DTT-SD: Companies interested in launching a new multiplex dedicated to additional standard definition digital television services.

Table 4

Overview of the DTT economic modelling.

\begin{tabular}{|c|c|c|c|c|}
\hline \multirow[t]{2}{*}{ Scenarios } & \multicolumn{2}{|l|}{ DTT-SD } & \multicolumn{2}{|l|}{ DTT-HD } \\
\hline & Low value & High value & Low value & High value \\
\hline $\begin{array}{l}\text { Ofcom value ( } f b n \text { ) } \\
\text { (producer + consumer } \\
\quad \text { value) }\end{array}$ & 0.5 & 3 & 1 & 3.5 \\
\hline Number of agents & 1 & 2 & 1 & 2 \\
\hline Spectrum acquired & 1 multiplex & 2 multiplex & 1 multiplex & 2 multiplex \\
\hline Main characteristics & $\begin{array}{l}\text { Low demand for incremental } \\
\text { channels }\end{array}$ & $\begin{array}{l}\text { High demand for incremental } \\
\text { channels }\end{array}$ & $\begin{array}{l}\text { Low value of } \mathrm{HD} \\
\text { channels }\end{array}$ & $\begin{array}{l}\text { High demand for } \mathrm{HD} \\
\text { channels }\end{array}$ \\
\hline "Adapted" value (€M) & Min & $\operatorname{Max}$ & Min & Max \\
\hline & 185 & 556 & 371 & 649 \\
\hline
\end{tabular}

Table 5

Overview of the mobile economic modelling.

\begin{tabular}{|c|c|c|c|c|c|c|}
\hline \multirow[t]{2}{*}{ Scenarios } & \multicolumn{2}{|c|}{ Mobile multimedia } & \multicolumn{2}{|c|}{ Mobile - voice and data } & \multicolumn{2}{|l|}{ Mobile - data centric } \\
\hline & Low value & High value & Low value & High value & Low value & High value \\
\hline $\begin{array}{l}\text { ofcom value }(\boldsymbol{f} b n) \\
\text { (producer + consumer } \\
\quad \text { value) }\end{array}$ & 0.3 & 3 & 0.5 & 2 & 1 & 2.5 \\
\hline Number of agents & 2 & 2 & 3 & 3 & 2 & 2 \\
\hline Spectrum acquired & $\begin{array}{l}24 \\
\text { mobileTV } \\
\text { channels }\end{array}$ & $\begin{array}{l}24 \text { mobileTV } \\
\text { channels }\end{array}$ & $10 \mathrm{MHz}$ & $10 \mathrm{MHz}$ & $24 \mathrm{MHz}$ & $24 \mathrm{MHz}$ \\
\hline Main characteristics & $\begin{array}{l}\text { Niche } \\
\text { market. } \\
\text { Urban areas }\end{array}$ & $\begin{array}{l}\text { High demand. } \\
\text { Some adoption } \\
\text { delay }\end{array}$ & $\begin{array}{l}\text { Operators possess } \\
\text { some } 900 \mathrm{MHz} \\
\text { spectrum. }\end{array}$ & $\begin{array}{l}\text { First low frequency } \\
\text { spectrum (below } \\
1 \mathrm{GHz} \text { ) }\end{array}$ & $\begin{array}{l}\text { Moderate demand. } \\
\text { Incumbents. } \\
\text { Available sites }\end{array}$ & $\begin{array}{l}\text { High demand. } \\
\text { New entrants. No } \\
\text { sites }\end{array}$ \\
\hline \multirow[t]{2}{*}{ “Adapted" value (€M) } & Min & $\operatorname{Max}$ & Min & $\operatorname{Max}$ & Min & $\operatorname{Max}$ \\
\hline & 56 & 556 & 62 & 247 & 185 & 463 \\
\hline
\end{tabular}

Table 6

Complement and substitution effects between lots and multiplication coefficients.

\begin{tabular}{|c|c|c|c|c|c|c|c|c|c|c|}
\hline \multirow{2}{*}{$\begin{array}{l}\text { Number of } \\
\text { lots }\end{array}$} & \multicolumn{2}{|l|}{ DTT-SD } & \multicolumn{2}{|l|}{ DTT-HD } & \multicolumn{2}{|c|}{ Mobile multimedia } & \multicolumn{2}{|c|}{ Mobile - voice and data } & \multicolumn{2}{|c|}{ Mobile - data centric } \\
\hline & $\begin{array}{l}\text { Value of } \\
\text { the lot }\end{array}$ & $\begin{array}{l}\text { Multipl. } \\
\text { coeff. }\end{array}$ & $\begin{array}{l}\text { Value of } \\
\text { the lot }\end{array}$ & $\begin{array}{l}\text { Multipl. } \\
\text { coeff. }\end{array}$ & $\begin{array}{l}\text { Value of } \\
\text { the lot }\end{array}$ & $\begin{array}{l}\text { Multipl. } \\
\text { coeff. }\end{array}$ & $\begin{array}{l}\text { Value of } \\
\text { the lot }\end{array}$ & $\begin{array}{l}\text { Multipl. } \\
\text { coeff. }\end{array}$ & $\begin{array}{l}\text { Value of } \\
\text { the lot }\end{array}$ & $\begin{array}{l}\text { Multipl. } \\
\text { coeff. }\end{array}$ \\
\hline 1 & & & & & 0.75 & 0.375 & 0.80 & 0.400 & 0.50 & 0.167 \\
\hline 2 & & & & & 1.00 & 1.000 & 1.00 & 1.000 & 0.75 & 0.500 \\
\hline 3 & 0.40 & 0.200 & 0.25 & 0.125 & 0.80 & 1.400 & 0.80 & 1.400 & 1.00 & 1.000 \\
\hline 4 & 0.65 & 0.433 & 0.50 & 0.333 & 0.60 & 1.700 & 0.60 & 1.700 & 0.90 & 1.300 \\
\hline 5 & 0.85 & 0.708 & 0.75 & 0.625 & 0.40 & 1.900 & 0.40 & 1.900 & 0.80 & 1.567 \\
\hline 6 & 1.00 & 1.000 & 1.00 & 1.000 & 0.20 & 2.000 & 0.20 & 2.000 & 0.70 & 1.800 \\
\hline 7 & 0.90 & 1.150 & 0.95 & 1.158 & & & 0.10 & 2.050 & 0.50 & 1.967 \\
\hline 8 & 0.80 & 1.283 & 0.90 & 1.308 & & & 0.05 & 2.075 & 0.25 & 2.050 \\
\hline 9 & 0.65 & 1.392 & 0.85 & 1.450 & & & & & & \\
\hline 10 & 0.50 & 1.475 & 0.75 & 1.575 & & & & & & \\
\hline 11 & 0.35 & 1.533 & 0.65 & 1.683 & & & & & & \\
\hline 12 & 0.20 & 1.567 & 0.55 & 1.775 & & & & & & \\
\hline 13 & & & 0.40 & 1.842 & & & & & & \\
\hline 14 & & & 0.25 & 1.883 & & & & & & \\
\hline 15 & & & 0.10 & 1.900 & & & & & & \\
\hline
\end{tabular}


- DTT-HD: Same, but high definition services.

- Mobile multimedia: Companies interested in delivering a range of services to handheld devices. These could include data, music and services such as mobile TV.

- Mobile data centric: Companies interested in rolling out a broadband service using a newer technology (e.g. variants of the already used 3G standards, mobile WiMAX or even LTE or ultra mobile broadband).

- Mobile voice and data: Companies interested in acquiring spectrum to augment current $3 \mathrm{G}$ services that focus on both voice and data.

Tables 4 and 5 present the main characteristics of the Ofcom scenarios from which the bidders' values intervals are derived.

Table 6 presents complement and substitution effects between lots and the resultant coefficient factor that multiplies values obtained for the optimum number of lots.

\section{Appendix B. Annex II}

\section{B.1. Scenario $N$}

\section{Frequency of lots earned by each bidder}

\section{$\begin{array}{lllllllllllllll}\text { B1 } & \text { B2 } & \text { B3 } & \text { B4 } & \text { B5 } & \text { B6 } & \text { B7 } & \text { B8 } & \text { B9 } & \text { B10 } & \text { B11 } & \text { B12 } & \text { B13 } & \text { B14 } & \text { B15 }\end{array}$}

$\begin{array}{rrrrrrrrrrrrrrrr}0 & 100 & 99 & 100 & 32 & 100 & 20 & 52 & 74 & 100 & 93 & 76 & 76 & 47 & 55 & 13 \\ 1 & 0 & 0 & 0 & 1 & 0 & 1 & 1 & 5 & 0 & 0 & 2 & 0 & 0 & 4 & 0 \\ 2 & 0 & 0 & 0 & 15 & 0 & 25 & 21 & 10 & 0 & 0 & 16 & 0 & 0 & 27 & 13 \\ 3 & 0 & 0 & 0 & 27 & 0 & 30 & 12 & 5 & 0 & 0 & 6 & 12 & 25 & 9 & 20 \\ 4 & 0 & 0 & 0 & 21 & 0 & 19 & 6 & 0 & 0 & 0 & 0 & 8 & 18 & 4 & 37 \\ 5 & 0 & 0 & 0 & 4 & 0 & 3 & 6 & 6 & 0 & 0 & 0 & 3 & 4 & 1 & 15 \\ 6 & 0 & 0 & 0 & 0 & 0 & 2 & 2 & 0 & 0 & 6 & 0 & 1 & 3 & 0 & 2 \\ 7 & 0 & 1 & 0 & 0 & 0 & 0 & 0 & 0 & 0 & 0 & 0 & 0 & 3 & 0 & 0 \\ 8 & 0 & 0 & 0 & 0 & 0 & 0 & 0 & 0 & 0 & 1 & 0 & 0 & 0 & 0 & 0\end{array}$

Price paid per lot (€M)

\begin{tabular}{|lrrrrrrrrrrrr} 
& \multicolumn{1}{c}{ B2 } & \multicolumn{1}{c}{ B4 } & \multicolumn{1}{c}{ B6 } & \multicolumn{1}{c}{ B7 } & \multicolumn{1}{c}{ B8 } & \multicolumn{1}{c}{ B10 } & \multicolumn{1}{c}{ B11 } & \multicolumn{1}{c}{ B12 } & \multicolumn{1}{c}{ B13 } & \multicolumn{1}{c}{ B14 } & \multicolumn{1}{c}{ B15 } \\
\hline Mean & 78.4 & 139.2 & 137.0 & 109.8 & 91.5 & 94.5 & 92.2 & 104.5 & 114.8 & 101.9 & 159.2 \\
Stand. Dev. & & 25.3 & 28.1 & 14.2 & 29.1 & 3.9 & 30.1 & 10.3 & 31.1 & 18.1 & 32.1 \\
Max & 78.4 & 185.6 & 191.7 & 136.7 & 107.2 & 97.3 & 109.8 & 117.5 & 136.5 & 135.1 & 211.9 \\
Min & 78.4 & 67.1 & 63.8 & 74.2 & 51.7 & 86.2 & 44.5 & 70.5 & 87.5 & 57.6 & 97.2
\end{tabular}

Seller's income $(€ M)$

\begin{tabular}{|l|rr|}
\cline { 2 - 3 } \multicolumn{1}{c|}{} & \multicolumn{1}{c|}{ Total } & \multicolumn{1}{c|}{ Per lot } \\
\hline Mean & 1927.6 & 128.5 \\
\hline Stand. Dev. & 215.8 & 14.5 \\
Max & 2473.6 & 164.9 \\
Min & 1310.5 & 87.4 \\
\hline
\end{tabular}


Frequency of lots earned by each bidder

\section{B1 $\quad$ B2 $\quad$ B3 $\quad$ B4 $\quad$ B9 $\quad$ B10}

\begin{tabular}{|c|c|c|c|c|c|}
\hline $\begin{array}{ll}0 & 91\end{array}$ & 54 & 72 & 99 & 63 & 48 \\
\hline 0 & 0 & 0 & 0 & 0 & \\
\hline 0 & 0 & 0 & 0 & 0 & \\
\hline 0 & 0 & 0 & 0 & 0 & \\
\hline 0 & 0 & 0 & 0 & 0 & \\
\hline 4 & 2 & 0 & 0 & 2 & \\
\hline 5 & 35 & 26 & 1 & 29 & \\
\hline 0 & 2 & 0 & 0 & 4 & \\
\hline 0 & 0 & 0 & 0 & 0 & \\
\hline 0 & 0 & 0 & 0 & 0 & \\
\hline 0 & 0 & 0 & 0 & 0 & \\
\hline 0 & 2 & 1 & 0 & 1 & \\
\hline 0 & 5 & 1 & 0 & 1 & 1 \\
\hline 100 & 100 & 100 & 100 & 100 & 10 \\
\hline
\end{tabular}

Price paid per lot $(€ M)$

\begin{tabular}{lrrrrrr} 
& \multicolumn{1}{c}{ B1 } & \multicolumn{1}{c}{ B2 } & \multicolumn{1}{c}{ B3 } & \multicolumn{1}{c}{ B4 } & \multicolumn{1}{c}{ B9 } & B10 \\
\hline Mean & 51.2 & 67.5 & 66.2 & 47.3 & 69.0 & 75.4 \\
St. Dev. & 7.1 & 12.7 & 8.8 & & 9.9 & 12.4 \\
Max & 61.3 & 85.7 & 76.1 & 47.3 & 82.7 & 96.1 \\
Min & 44.1 & 34.4 & 48.1 & 47.3 & 33.8 & 47.5 \\
\multicolumn{5}{c}{ DTT }
\end{tabular}

Mean
St. Dev.
Max
Min

$\begin{array}{llllll}\text { B6 } & \text { B7 } & \text { B8 } & \text { B11 } & \text { B12 } & \text { B13 }\end{array}$

$\begin{array}{llllll}52.1 & 81.9 & 88.2 & 79.6 & 91.8 & 107.4\end{array}$

$\begin{array}{lllllll}16.5 & 16.8 & 17.2 & 17.5 & 20.8 & 17.1\end{array}$

$\begin{array}{llllll}63.8 & 108.9 & 107.3 & 103.7 & 115.8 & 138.5\end{array}$

$\begin{array}{llllll}40.5 & 50.7 & 40.6 & 48.7 & 37.2 & 64.1\end{array}$

MobComm

Seller's income $(\mathrm{EM})$

\begin{tabular}{|lrrrr|}
\cline { 2 - 4 } \multicolumn{1}{c}{} & \multicolumn{1}{c}{ Total } & \multicolumn{1}{c}{ Per lot } & \multicolumn{1}{c|}{ Total } & \multicolumn{1}{c|}{ Per lot } \\
\hline Mean & 832.0 & 69.3 & 288.9 & 96.3 \\
Stand. Dev. & 122.0 & 10.2 & 50.9 & 17.0 \\
Max & 1072.3 & 89.4 & 415.5 & 138.5 \\
Min & 408.9 & 34.1 & 169.7 & 56.6
\end{tabular}

Total Per lot

1120.9

74.7 
Frequency of lots earned by each bidder

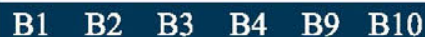

\begin{tabular}{|c|c|c|c|c|c|}
\hline 96 & 73 & 92 & 99 & 85 & 55 \\
\hline 0 & 0 & 0 & 0 & 0 & \\
\hline 0 & 0 & 0 & 0 & 0 & \\
\hline 0 & 0 & 0 & 0 & 0 & \\
\hline 0 & 0 & 0 & 0 & 0 & \\
\hline 0 & 0 & 0 & 0 & 0 & \\
\hline 0 & 0 & 0 & 0 & 0 & \\
\hline 0 & 3 & 0 & 0 & 4 & \\
\hline 4 & 24 & 8 & 1 & 11 & 36 \\
\hline 100 & 100 & 100 & 100 & 100 & 10 \\
\hline
\end{tabular}

\section{B4 B6 B7 B14 B15}

$\begin{array}{rrrrrr}0 & 68 & 79 & 95 & 96 & 53 \\ 1 & 6 & 3 & 3 & 1 & 5 \\ 2 & 26 & 18 & 2 & 3 & 42 \\ & 100 & 100 & 100 & 100 & 100\end{array}$

MobMultimedia

$\begin{array}{lllllll}\text { B5 } & \text { B6 } & \text { B7 } & \text { B8 } & \text { B11 } & \text { B12 } & \text { B13 }\end{array}$

$\begin{array}{rrrrrrrr}0 & 99 & 99 & 79 & 56 & 72 & 69 & 53 \\ 1 & 1 & 1 & 5 & 15 & 6 & 0 & 0 \\ 2 & 0 & 0 & 13 & 16 & 19 & 1 & 0 \\ 3 & 0 & 0 & 3 & 5 & 3 & 16 & 18 \\ 4 & 0 & 0 & 0 & 0 & 0 & 6 & 10 \\ 5 & 0 & 0 & 0 & 8 & 0 & 8 & 19\end{array}$

$\begin{array}{lllllll}100 & 100 & 100 & 100 & 100 & 100 & 100\end{array}$

MobComm

Price paid per lot (€M)

\begin{tabular}{|c|c|c|c|c|c|c|}
\hline & B1 & B2 & B3 & B4 & B9 & B10 \\
\hline Mean & 57.2 & 71.1 & 58.4 & 38.7 & 74.1 & 79.5 \\
\hline St. Dev. & 10.5 & 10.7 & 11.7 & & 4.8 & 10.6 \\
\hline Max & 65.3 & 85.2 & 73.1 & 38.7 & 80.2 & 96.5 \\
\hline Min & 42.8 & 44.2 & 38.0 & 38.7 & 67.5 & 49.4 \\
\hline
\end{tabular}

\begin{tabular}{|c|c|c|c|c|c|}
\hline & B4 & B6 & B7 & B14 & B15 \\
\hline Mean & 127.3 & 138.0 & 104.7 & 89.8 & 153.4 \\
\hline St. Dev. & 27.5 & 27.6 & 20.3 & 26.0 & 36.2 \\
\hline Max & 186.2 & 179.1 & 134.6 & 119.0 & 224.9 \\
\hline Min & 91.4 & 89.1 & 88.3 & 55.8 & 74.4 \\
\hline
\end{tabular}

$\begin{array}{lllllll}\text { B5 } & \text { B6 } & \text { B7 } & \text { B8 } & \text { B11 } & \text { B12 } & \text { B13 }\end{array}$

\begin{tabular}{|c|c|c|c|c|c|c|c|}
\hline Mean & 40.5 & 42.5 & 82.9 & 83.5 & 87.5 & 99.4 & 109.3 \\
\hline St. Dev. & & & 14.6 & 15.7 & 12.9 & 12.8 & 20.7 \\
\hline Max & 40.5 & 42.5 & 106.4 & 110.1 & 108.5 & 117.9 & 138.9 \\
\hline Min & 40.5 & 42.5 & 49.9 & 58.3 & 59.1 & 74.3 & 54.4 \\
\hline
\end{tabular}

Seller's income $(€ \mathrm{M})$

\begin{tabular}{|c|c|c|c|c|c|c|c|c|}
\hline & Total & Per lot & Total & Per lot & Total & Per lot & Total & Per lot \\
\hline Mean & 573.8 & 71.7 & 283.9 & 141.9 & 491.4 & 98.3 & 1349.1 & 89.9 \\
\hline Stand. Dev. & 91.6 & 11.4 & 67.4 & 33.7 & 72.5 & 14.5 & & \\
\hline $\operatorname{Max}$ & 745.9 & 93.2 & 449.8 & 224.9 & 643.8 & 128.8 & & \\
\hline Min & 303.8 & 38.0 & 144.9 & 72.5 & 281.3 & 56.3 & & \\
\hline
\end{tabular}


Frequency of lots earned by each bidder

\section{B1 $\quad$ B2 $\quad$ B3 $\quad$ B4 $\quad$ B9 $\quad$ B10}

\begin{tabular}{rrrrrrr}
0 & 84 & 81 & 92 & 99 & 73 & 71 \\
1 & 0 & 0 & 0 & 0 & 0 & 0 \\
2 & 0 & 0 & 0 & 0 & 0 & 0 \\
3 & 0 & 0 & 0 & 0 & 0 & 0 \\
4 & 16 & 19 & 8 & 1 & 27 & 29 \\
100 & 100 & 100 & 100 & 100 & 100 \\
\multicolumn{5}{c}{ DTT } \\
& \multicolumn{1}{c}{}
\end{tabular}

$\begin{array}{lllll}\text { B4 } & \text { B6 } & \text { B7 } & \text { B14 } & \text { B15 }\end{array}$

$\begin{array}{rrrrrr}0 & 34 & 35 & 71 & 81 & 13 \\ 1 & 8 & 13 & 5 & 5 & 6 \\ 2 & 27 & 24 & 17 & 8 & 18 \\ 3 & 16 & 19 & 6 & 5 & 36 \\ 4 & 12 & 6 & 1 & 1 & 18 \\ 5 & 2 & 3 & 0 & 0 & 8 \\ 6 & 1 & 0 & 0 & 0 & 1 \\ 7 & 0 & 0 & 0 & 0 & 0 \\ & 100 & 100 & 100 & 100 & 100\end{array}$

MobMultimedia

B5 $\quad$ B6 $\quad$ B7 $\quad$ B8 $\quad$ B11 $\quad$ B12 $\quad$ B13

$\begin{array}{rrrrrrrr}0 & 98 & 100 & 73 & 72 & 68 & 76 & 51 \\ 1 & 2 & 0 & 12 & 19 & 13 & 0 & 0 \\ 2 & 0 & 0 & 12 & 6 & 14 & 0 & 1 \\ 3 & 0 & 0 & 2 & 2 & 3 & 13 & 24 \\ 4 & 0 & 0 & 1 & 1 & 2 & 11 & 24 \\ & 100 & 100 & 100 & 100 & 100 & 100 & 100\end{array}$

MobComm

Price paid per lot $(€ \mathrm{M})$

\begin{tabular}{|c|c|c|c|c|c|c|}
\hline & B1 & B2 & B3 & B4 & B9 & B10 \\
\hline Mean & 36.8 & 37.0 & 32.6 & 23.5 & 43.2 & 42.4 \\
\hline St. Dev. & 5.1 & 4.6 & 2.7 & & 5.4 & 3.9 \\
\hline Max & 45.0 & 43.2 & 37.8 & 23.5 & 50.8 & 48.6 \\
\hline Min & 28.4 & 29.8 & 29.3 & 23.5 & 29.1 & 33.8 \\
\hline
\end{tabular}

\begin{tabular}{|c|c|c|c|c|c|}
\hline & B4 & B6 & B7 & B14 & B15 \\
\hline Mean & 135.2 & 125.8 & 108.1 & 99.2 & 156.9 \\
\hline St. Dev. & 34.1 & 35.0 & 22.5 & 27.7 & 47.1 \\
\hline Max & 186.0 & 188.6 & 135.8 & 133.4 & 231.8 \\
\hline Min & 42.2 & 36.6 & 57.5 & 42.8 & 14.2 \\
\hline
\end{tabular}

$\begin{array}{llllll}\text { B5 } & \text { B7 } & \text { B8 } & \text { B11 } & \text { B12 } & \text { B13 }\end{array}$

Mean
St. Dev.
Max
Min

$\begin{array}{llllll}44.3 & 80.6 & 73.9 & 82.1 & 104.4 & 115.6\end{array}$

$\begin{array}{llllll}7.7 & 16.1 & 16.1 & 15.1 & 10.1 & 14.1\end{array}$

$\begin{array}{llllll}49.7 & 111.0 & 111.2 & 109.0 & 115.8 & 139.0\end{array}$

$\begin{array}{lllllll}38.8 & 52.8 & 45.7 & 53.6 & 80.9 & 79.4\end{array}$

\section{MobComm}

Seller's income (€M)

\begin{tabular}{|c|c|c|c|c|c|c|c|c|}
\hline & Total & Per lot & Total & Per lot & Total & Per lot & Total & Per lot \\
\hline Mean & 158.9 & 39.7 & 1006.0 & 143.7 & 404.0 & 101.0 & 1568.9 & 104.6 \\
\hline Stand. Dev. & 23.7 & 5.9 & 158.0 & 22.6 & 58.1 & 14.5 & & \\
\hline $\operatorname{Max}$ & 203.2 & 50.8 & 1314.6 & 187.8 & 525.4 & 131.3 & & \\
\hline Min & 94.0 & 23.5 & 368.6 & 52.7 & 259.7 & 64.9 & & \\
\hline
\end{tabular}


Frequency of lots earned by each bidder

\section{B4 B6 B7 B14 B15}

$\begin{array}{rrrrrr}0 & 47 & 50 & 98 & 93 & 12 \\ 1 & 13 & 11 & 0 & 1 & 4 \\ 2 & 24 & 23 & 2 & 6 & 29 \\ 3 & 11 & 15 & 0 & 0 & 34 \\ 4 & 2 & 0 & 0 & 0 & 10 \\ 5 & 3 & 1 & 0 & 0 & 11 \\ & 100 & 100 & 100 & 100 & 100\end{array}$

MobMultimedia

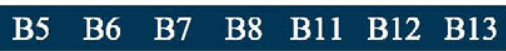

\begin{tabular}{|c|c|c|c|c|c|c|}
\hline 92 & 93 & 38 & 48 & 51 & 44 & 40 \\
\hline 4 & 3 & 6 & 5 & 8 & 0 & 1 \\
\hline 2 & 2 & 36 & 18 & 24 & 0 & 0 \\
\hline 3 & 2 & 13 & 4 & 15 & 17 & 12 \\
\hline 0 & 0 & 7 & 1 & 2 & 17 & 14 \\
\hline 0 & 0 & 0 & 12 & 0 & 13 & 19 \\
\hline 0 & 0 & 0 & 5 & 0 & 7 & 9 \\
\hline 0 & 0 & 0 & 2 & 0 & 2 & 5 \\
\hline 0 & 0 & 0 & 2 & 0 & 0 & 0 \\
\hline 0 & 0 & 0 & 3 & 0 & 0 & 0 \\
\hline 10 & 0 & 0 & 0 & 0 & 0 & 0 \\
\hline 100 & 100 & 100 & 100 & 100 & 100 & 100 \\
\hline
\end{tabular}

MobComm

Price paid per lot $(€ M)$

\begin{tabular}{lrrrrr} 
& \multicolumn{1}{c}{ B4 } & \multicolumn{1}{c}{ B6 } & \multicolumn{1}{c}{ B7 } & \multicolumn{1}{c}{ B14 } & B15 \\
\hline Mean & 128.1 & 134.3 & 113.0 & 113.1 & 171.5 \\
St. Dev. & 38.1 & 35.5 & 17.9 & 28.7 & 42.0 \\
Max & 188.8 & 193.3 & 125.7 & 132.6 & 244.0 \\
Min & 32.0 & 56.1 & 100.3 & 60.8 & 59.4 \\
\multicolumn{5}{c}{ MobMultimedia } \\
\end{tabular}

Seller's income $(€ \mathrm{M})$

\section{Total}

Mean

776.3

125.0

1008.5

464.0

\section{Per lot}

155.3

25.0

201.7

92.8

\begin{tabular}{|rr|}
\hline \multicolumn{1}{|c|}{ Total } & \multicolumn{1}{c|}{ Per lot } \\
\hline 914.0 & 91.4 \\
131.5 & 93.0 \\
1161.3 & 13.2 \\
550.4 & 116.1
\end{tabular}

$\begin{array}{lllllll}\text { B5 } & \text { B6 } & \text { B7 } & \text { B8 } & \text { B11 } & \text { B12 } & \text { B13 }\end{array}$

$\begin{array}{llllllll}\text { Mean } & 56.3 & 53.4 & 81.6 & 82.9 & 81.6 & 94.4 & 99.0\end{array}$

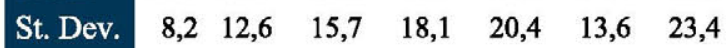

$\begin{array}{llllllll}\text { Max } & 68,2 & 67,8 & 108,5 & 106,2 & 110,2 & 116,3 & 133,5\end{array}$

$\begin{array}{llllllll}\text { Min } & 43,6 & 39,6 & 40,8 & 26,3 & 31,1 & 60,7 & 37,1\end{array}$

\section{MobComm}

\section{References}

Alleman, J., Madden, G., Kim, H.J., 2008. Real options methodology applied to the ICT sector: a survey. Communications \& Strategies 70, $27-44$.

Analysys Mason, DotEcon and Hogan\&Hartson, 2009. Exploiting the digital dividend - a European approach. Report from the European Commission 13496-

13436. Available from: <http://www.analysysmason.com/Consulting/Services/Strategy-consulting/Spectrum-management/Digital-dividend/ Exploiting-the-digital-dividend-a-European-approach/Final-report-for-the-European-Commission/>.

Ausubel, L.M., Cramton, P., McAfee, P., McMillan, J., 1997. Synergies in wireless telephony: evidence from the broadband PCS auctions. Journal of Economics and Management Strategy 6 (3), 497-527.

Cramton, P., 2007. How best to auction oil rights. In: Humphreys, M., Sachs, J.D., Stiglitz, J.E. (Eds.), Escaping the Resource Curse. Columbia University Press, New York, pp. 114-151.

Cramton, P., 2002. Spectrum auctions. In: Cave, M.E., Majumdar, S.K., Vogelsang, 1. (Eds.), Handbook of Telecommunications Economics - Structure, regulation and competition. Elsevier, Amsterdam, pp. 605-639. 
Feijóo, C., Gómez-Barroso, J.L., Mochón, A., 2009. Reforms in spectrum management policy. In: Lee, 1. (Ed.), Handbook of Research on Telecommunications Planning and Management for Business. IGl Global, Hershey - London, pp. 33-47.

Forge, S., Blackman, C., Bohlin, E., 2008. Economic impacts of alternative uses of the digital dividend. Intereconomics 43 (3), 149-162.

Hart, P.E., Nilsson, N.J., Raphael, B., 1968. A formal basis for the heuristic determination of minimum cost paths. IEEE Transactions on Systems Science and Cybernetics $4(2), 100-107$.

Hazlett, T.W., Muñoz, R., 2008. A welfare analysis of spectrum allocation policies. George Mason University Law and Economics Research Paper Series 06-28. Available from: <http://ssrn.com/abstract_id $=908717>$.

Lyoo, T.H., Jeong, J., Lee, H.J., Lee, J.D., 2006. Efficient spectrum policy using real options and game theoretic methods. In: Cooper, R., Madden, G., Lloyd, A. Schipp, M. (Eds.), The Economics of Online Markets and ICT Networks. Physica-Verlag, Heidelberg, pp. 157-166.

Ofcom, 2007. Digital dividend review - a statement on our approach to awarding the digital dividend. United Kingdom Office of Communications. Available from: 〈http://www.ofcom.org.uk/consult/condocs/ddr/statement/statement.pdf〉.

Ofcom, 2006. Digital dividend review - document consulting on the proposed approach to the award of the digital dividend spectrum (470-862 MHz). United Kingdom Office of Communications. Available from: <http://www.ofcom.org.uk/consult/condocs/ddr/ddrmain.pdf>.

Oliver\&Ohlbaum Associates and DotEcon, 2008. The effects of a market-based approach to spectrum management of UHF and the impact on digital terrestrial broadcasting. Available from: <http://www.ebu.ch/CMSimages/en/UHF\%20Spectrum\%20Management_ENG_FINAL_tcm6-57755.pdf>.

Sáez, Y., Mochón, A., Gómez-Barroso, J.L., Isasi, P., 2008. Testing BOI and BOB algorithms for solving the winner determination problem in radio spectrum auctions. In: Proceedings of the 8th International conference on Hybrid Intelligent Systems (HIS 2008). IEEE Computer Society Press, Barcelona, pp. 732737.

Sweet, R., Viehoff, I., Linardatos, D., Kalouptsidis, N., 2002. Marginal value-based pricing of additional spectrum assigned to cellular telephony operators. Information Economics and Policy 14 (3), 371-384. 